\title{
CONTROLE ESTATÍSTICO DE PROCESSO APLICADO À COLHEITA MECANIZADA DE MILHO
}

Cristiano Zerbato ${ }^{1}$, Fábio Alexandre Cavichioli ${ }^{2}$, Marcelo Boamorte Raveli ${ }^{3}$, Mateus Marrafon ${ }^{4}$, Rouverson Pereira da Silva ${ }^{5}$

\section{RESUMO}

Evitar as perdas decorridas na colheita mecanizada na cultura de milho é um fator de extrema importância para a produtividade de uma área agrícola, sendo a plataforma de corte da colhedora o local onde ocorrem os maiores índices de perdas. Objetivou-se neste trabalho avaliar as perdas quantitativas na colheita mecanizada de milho utilizando duas plataformas de corte em dois híbridos de milho, utilizando ferramentas de qualidade do processo. Os tratamentos constituíram-se de duas plataformas de corte (A e B) e duas cultivares de milho (1 e 2). Foram avaliadas as perdas nas plataformas de corte e as perdas totais. Utilizaram-se a estatística descritiva, a análise de variância e as cartas de controle para avaliação da qualidade do processo. Observou-se que no milho 1, a plataforma A obteve o maior valor médio de perdas na plataforma e mostrou instabilidade do processo, porém para perdas totais a plataforma B foi a que se mostrou fora de controle, entretanto sua média não diferiu da outra. Para o milho 2, tanto as perdas na plataforma quanto as totais foram menores na plataforma B, a qual mostrou instabilidade do processo para perdas totais, todavia com menor variação indicada pelos limites de controle.

Palavras-chave: cartas de controle, colhedora, perdas, Zea mays.

\section{ABSTRACT \\ STATISTICAL PROCESS CONTROL APPLIED TO MECHANIZED MAIZE HARVEST WITH DIFFERENT CUTTING PLATFORMS}

Avoiding losses in the mechanized maize harvesting process is a factor of extreme importance for field productivity, and the cutting platform is where greatest loss occurs. The purpose of the project was to evaluate mechanical maize harvest losses using two cutting platforms and two maize hybrids, utilizing quality and statistical process control tools. The treatments consisted of two cutting platforms (A and B) and two maize hybrids (1 and 2). Losses were assessed with respect to the cutting platforms and total losses. Descriptive statistics, analysis of variance and control charts were used to evaluate quality of the process. It was noticed that for 'maize hybrid 1', 'platform A' had the highest mean value of losses by the platform and showed process instability; however platform B presented the greatest total process losses, but its average did not differ from the other. For 'maize hybrid 2', both losses at the platform and total losses were lower in platform $\mathrm{B}$, which showed process instable with respect to total losses, but with less variation indicated by the control limits.

Keywords: control charts, harvester, losses, Zea mays.

\section{Recebido para publicação em 04/12/2012. Aprovado em 11/03/2013.}

1 - Engenheiro Agrônomo, Doutorando na FCAV - UNESP/Jaboticabal SP

2 - Engenheiro Agrônomo, Doutorando na FCAV - UNESP/Jaboticabal SP

3 - Engenheiro Agrônomo, Doutorando na FCAV - UNESP/Jaboticabal SP

4 - Engenheiro Agrônomo, Doutorando na FCAV - UNESP/Jaboticabal SP

5 - 르genheiro Agrícola, Professor Doutor na FCAV - UNESP/Jaboticabal, e-mail autor: cristianozerbato@hotmail.com 


\section{INTRODUÇÃO}

O milho (Zea mays) é uma cultura de grande importância na economia brasileira, com área de mais de 15 milhões de hectares semeados na safra 2011/2012, com produção em torno 66 milhões de toneladas, e produtividade média na região sudeste do Brasil com $5500 \mathrm{~kg} \mathrm{ha}^{-1}$, considerando a safra anual (Conab 2012).

Para se tornar financeiramente viável, uma unidade produtora deverá possuir uma alta produtividade e uma tecnologia que consiga retirar com eficiência e agilidade os grãos produzidos pela cultura. Nesse ponto, a colheita mecanizada vem se aperfeiçoando cada vez mais, buscando diminuir as perdas de grãos no campo, realizando o trabalho cada vez mais rápido.

Para evitar as perdas na operação de colheita é necessário toda cautela possível, caso contrário todo o trabalho com os outros processos produtivos anteriores, como semeadura e tratos culturais, será perdido. Neste ponto, regulagens da colhedora, perícia do operador, porte da lavoura e a qualidade da operação são fatores decisivos para o sucesso de todo processo produtivo.

As perdas na colheita são influenciadas tanto por fatores inerentes à cultura em especial, como por fatores relacionados à colhedora. Um dos principais fatores que afetam as perdas na colheita de milho é a plataforma de corte, a qual realiza a primeira e principal etapa de colheita, com função de despigar, recolher e transportar as espigas para dentro da máquina, para que possa ser trilhadas.

Staggenborg et al. (2008) afirmam que as perdas na plataforma de colheita são maiores quando utilizadas plataformas de colheita de $0,80 \mathrm{~m}$ para colher milho cultivado a 0,40 ou $0,50 \mathrm{~m}$. Segundo Loureiro et al. (2012) a utilização de plataformas de colheita para milho cultivado em espaçamento reduzido apresenta grande aumento das perdas de plataforma.

O acamamento das plantas de milho também pode influenciar a eficiência da colheita mecânica (BRACHTVOGEL et al. 2012), onde dependendo da situação que se encontra uma lavoura no momento da colheita, as perdas são diretamente afetadas.

$\mathrm{O}$ investimento em plataformas de colheita segundo Dias et al. (2007), pode ser viável em lavouras com altas produtividades, ou em grandes extensões de cultivo, sendo que um alto investimento somente é justificado se houver um significativo efeito sobre a lucratividade da atividade, e as perdas na colheita é um fator muito importante para que não diminua a produção e assim obtenha sucesso com o negócio. Com isso, empresas do setor buscam novas alternativas e atualizações funcionais para melhor atender o mercado interno, sendo a importação de novas plataformas uma opção para suprir essa necessidade, para tanto, a mesma deve estar de acordo com a legislação brasileira.

O Controle Estatístico de Processo (CEP) tem como objetivo detectar alterações dos parâmetros de determinados processos para que os problemas possam ser corrigidos antes que muitos itens não conformes sejam produzidos (MINGOTI; FIDELIS, 2001). O controle de qualidade é perfeitamente adaptável ao sistema de produção agrícola. Com a correção e a eliminação de desperdícios e falhas, redução de custos e aumento da produtividade, inúmeras vantagens serão acrescidas à competitividade do campo (BONILLA, 1994). O emprego do CEP para avaliar e/ou monitorar a qualidade de operações agrícolas mecanizadas ainda é incipiente no Brasil, entretanto é possível encontrar trabalhos com aplicações de ferramentas do CEP na colheita mecanizada de feijão (SILVA et al., 2013), de café (CASSIA et al., 2013; CUSTODIO et al., 2012), de soja (CHIODEROLI et al., 2012) e de cana-deaçúcar (NORONHA et al., 2011).

Diante do exposto, objetivou-se neste trabalho avaliar as perdas quantitativas na colheita mecanizada de milho com auxílio de ferramentas que indicam a qualidade da operação, utilizando-se duas plataformas de corte e dois híbridos de milho.

\section{MATERIAL E MÉTODOS}

O experimento foi realizado em área do município de Uberaba - MG, Brasil, localizada nas proximidades das coordenadas geodésicas 19²0'53' latitude Sul e 47 57'04' longitude Oeste, com altitude média de $981 \mathrm{~m}$, relevo plano. O solo da área experimental foi classificado como Latossolo Vermelho-Amarelo de acordo com Embrapa (2006). Segundo a classificação de Köppen, o clima da região é do tipo Cwa, definido como clima temperado húmido com inverno seco e verão quente.

Os conjuntos de colhedoras e plataformas utilizadas foram: - Case IH modelo 2566 com sistema axial de trilha, equipada com plataforma de corte importada de origem italiana com largura de $6,10 \mathrm{~m}$, operando durante a colheita com velocidade média de deslocamento de 4,5 $\mathrm{km} \mathrm{h}^{-1}$ (2500 rpm no motor), rotação do cilindro trilhador regulada para $440 \mathrm{rpm}$, e com a abertura máxima $(30 \mathrm{~mm})$ do côncavo (plataforma A); - Case IH modelo 2388 com sistema axial de trilha, equipada com plataforma nacional de corte de $6,10 \mathrm{~m}$ de largura, operando durante a colheita com velocidade média de deslocamento de 4,5 $\mathrm{km} \mathrm{h}^{-1}$ (2500 rpm no motor), rotação do cilindro trilhador regulada para $440 \mathrm{rpm}$, e com a 
abertura máxima $(30 \mathrm{~mm}$ ) do côncavo (plataforma B). Pelo fato de uma plataforma ser nacional e a outra importada, possuem projetos de fabricação diferentes e dimensões dos componentes distintos, como os pesos de 2889 e $3980 \mathrm{~kg}$ e comprimento das chapas despigadoras de 0,65 e $0,86 \mathrm{~m}$ para a plataforma $\mathrm{A}$ e $\mathrm{B}$, respectivamente, sendo os divisores de linhas da primeira, fabricados de plástico e da segunda de metal.

A cultura estava implantada sobre sistema de semeadura direta, no espaçamento entre linhas de 0,50 m. Foram utilizados dois híbridos de milho, sendo um acamado e outro ereto, denominados de Milho 1 e Milho 2, respectivamente. A altura média de inserção das espigas em ambos os híbridos utilizados foi de $1,50 \mathrm{~m}$. O teor médio de água dos grãos no momento da colheita foi de $12,4 \%$, determinada por meio de medidor portátil. Para determinar a produtividade da cultura, foram coletadas espigas em dois metros de cada uma das três linhas avaliadas, posteriormente realizando-se a trilha das espigas e medindo a massa dos grãos, sendo os valores extrapolados para $\mathrm{kg}$ $\mathrm{ha}^{-1}(12 \%$ b.u. $)$, apresentando valores médios de 12.700 e $14.670 \mathrm{~kg} \mathrm{ha}^{-1}$, para os milhos 1 e 2 , respectivamente.

$\mathrm{Na}$ determinação das perdas foram utilizadas armações retangulares, construídas com duas barras metálicas e dois cordões de náilon, com medidas ajustáveis para obter a mesma largura das plataformas de corte das colhedoras em estudo, mantendo-se a área interna de $2,0 \mathrm{~m}^{2}$, segundo método proposto por Mesquita et al. (1998). Todos os grãos presentes dentro da armação foram coletados, sendo classificados como: perdas na plataforma e perdas totais. Não foram observadas perdas naturais anteriores à colheita. Para coletar as perdas na plataforma parou-se a colhedora e os mecanismos da plataforma de corte foram desligados. Em seguida deu-se marcha-a-ré na colhedora, a uma distância igual à metade do comprimento da máquina; colocou-se a armação na parte colhida em frente à colhedora e todos os grãos ali presentes, soltos ou nas espigas, foram recolhidos e pesados. Na medição das perdas totais, a amostragem ocorreu após passagem da máquina, sendo a armação posicionada atrás da colhedora, e os grãos presentes no seu interior, em espigas ou não, foram coletados e pesados. Quando foram encontradas perdas em espigas, a área de amostragem foi de $30 \mathrm{~m}^{2}$.

Os tratamentos foram constituídos em função de duas plataformas de corte em dois híbridos de milho, sendo que um dos híbridos estava acamado e o outro ereto no momento da colheita. Foram coletados 60 pontos amostrais espaçados $50 \times 12$ $\mathrm{m}$ entre si, sendo 15 pontos para cada tratamento.

Utilizando $^{-}$se estatística descritiva permitiu ${ }^{-}$se a visualização geral do comportamento dos dados (Vieira et al., 2002). Foram calculados a média aritmética, mediana, desvio-padrão e os coeficientes de variação, assimetria e curtose. A normalidade dos dados foi verificada pelo teste de Anderson-Darling, e quando assimétricos foram transformados para se atingir a normalidade, por meio da fórmula: $x$ ' $=1 / \sqrt{ } \mathrm{x}$. As médias obtidas foram comparadas pelo teste de Tukey a $5 \%$ de probabilidade quando houve significância na análise de variância pelo teste $\mathrm{F}$ de Snedecor, e foram representadas por meio dos diagramas de caixas (box plot).

Os métodos estatísticos utilizados para as determinações de qualidade do processo foram as cartas de controle para cada variável, que têm como linha central a média geral e amplitude média, bem como os limites superior e inferior de controle, definidos como LSC e LIC, calculados com base no desvio-padrão das variáveis (para LSC, média mais três vezes o desvio-padrão, e para LIC, média menos três vezes o desvio, quando maior que zero).

O diagrama de caixas é um gráfico que possibilita representar a distribuição de um conjunto de dados com base em alguns de seus parâmetros descritivos, como a mediana, o quartil inferior, o quartil superior, intervalo interquartil, e os valores mínimos e máximos. Esta análise permite avaliar a simetria e a dispersão dos resultados, bem como a existência ou não de pontos discrepantes nos mesmos, sendo especialmente adequado para a comparação de dois ou mais conjuntos de dados correspondentes às categorias de uma variável (Bonilla, 1995).

\section{RESULTADOS E DISCUSSÃO}

Para a maioria dos indicadores de qualidade, em ambos os tratamentos, observou-se a ocorrência de pontos discrepantes (outliers), que podem ser visualizados nos diagramas de caixa. Estes dados foram mantidos em todas as análises estatísticas realizadas, uma vez que estes pontos discrepantes fazem parte do processo e podem ajudar a identificar a ocorrência de causas especiais.

A estatística descritiva para a variável Perdas na plataforma e Totais no milho 1 se mostrou assimétrica para os tratamentos avaliados de acordo com o teste de Anderson-Darling (Figura 1).

Ambas variáveis apresentaram coeficiente de variação considerado alto segundo PimentelGomes e Garcia (2002) uma vez que a variabilidade de um atributo pode ser classificada conforme a magnitude do seu coeficiente de variação (FREDDI et al., 2006). Houve distribuição assimétrica com alongamento da curva mais à direita (coeficiente 
de assimetria positivo), indicando que há acúmulo de pontos abaixo da média que tendem a se afastar da mesma. Observa-se também que os coeficientes de curtose foram positivos, indicando distribuição leptocúrtica, ou seja, maior probabilidade de ter valores extremos e próximos à média, sendo a curva mais alongada do que a normal. Também se verifica que tanto para perdas na plataforma quanto para perdas totais, as médias da plataforma $\mathrm{B}$ sempre estiveram mais perto da mediana do que para a plataforma $\mathrm{A}$, mostrando maior variabilidade dos dados para esta, representado pela caixa com maior amplitude interquartílica no gráfico box-plot.

Observa-se que houve diferença somente para a variável perdas na plataforma, sendo que a plataforma A apresentou o maior valor médio de perdas do que a plataforma B. Não obstante a diferença significativa encontrada para as perdas na plataforma, mesmo a plataforma $\mathrm{A}$ apresentando $45,09 \mathrm{~kg} \mathrm{ha}^{-1}(0,35 \%$ da produtividade), situase abaixo do nível considerado admissível para perda na colheita de milho (PORTELLA, 2001), o qual não pode ultrapassar $2 \%$ com relação à produtividade. Observa-se também que não houve diferença para as perdas totais, indicando que após a passagem total da máquina as perdas se igualaram estatisticamente. Portanto a plataforma A foi responsável por quase $50 \%$ das perdas encontradas indicando que a mesma não executou um bom corte em condições de acamamento.

Perdas na Plataforma*

Perdas Totais

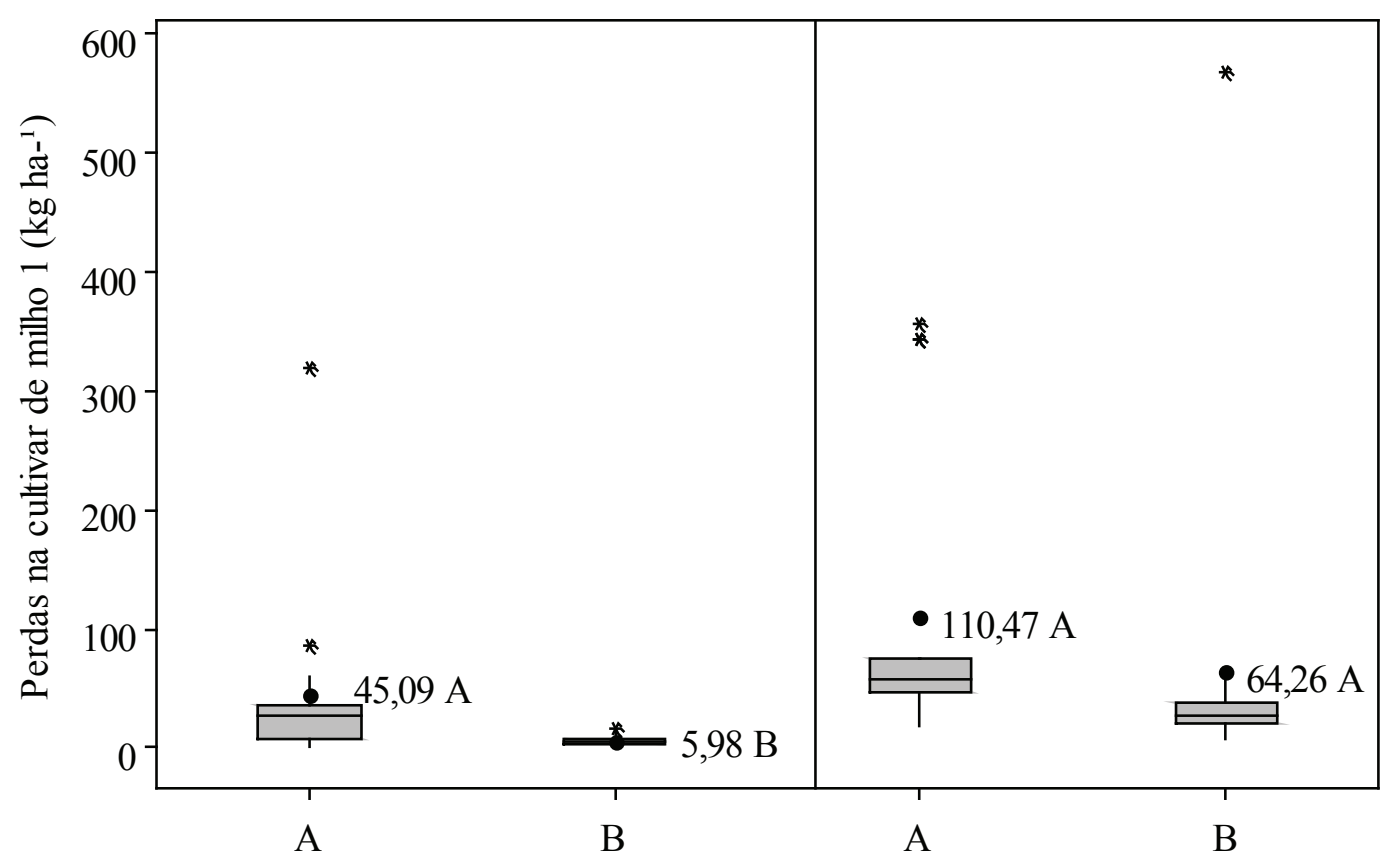

Plataformas

\begin{tabular}{lcccccc}
\hline \multicolumn{1}{c}{ Variável } & $\sigma^{* *}$ & Mediana & $\mathrm{Ck}$ & $\mathrm{Cs}$ & $\mathrm{CV}(\%)$ & $\mathrm{AD}$ \\
\hline Perdas na Plataforma Plat. & 58,80 & 8,10 & 23,34 & 4,65 & 130,08 & $5,977^{\mathrm{A}}$ \\
Perdas Totais & 131,9 & 39,30 & 6,09 & 2,57 & 50,98 & $5,877^{\mathrm{A}}$ \\
\hline
\end{tabular}

"Tratamentos: Plataforma A e B.

${ }^{* *} \sigma$ - Desvio padrão; Ck - Coeficiente de Curtose; Cs - Coeficiente de assimetria; CV - Coeficiente de variação; AD - Teste de normalidade de Anderson-Darling (A: distribuição Assimétrica); • - Média aritmética.

${ }^{* * *}$ Letras maiúsculas distintas diferem entre si, pelo teste de Tukey a $5 \%$.

Figura 1. Diagrama de caixa para as perdas na colheita mecanizada do cultivar milho 1.

\section{REVENG}




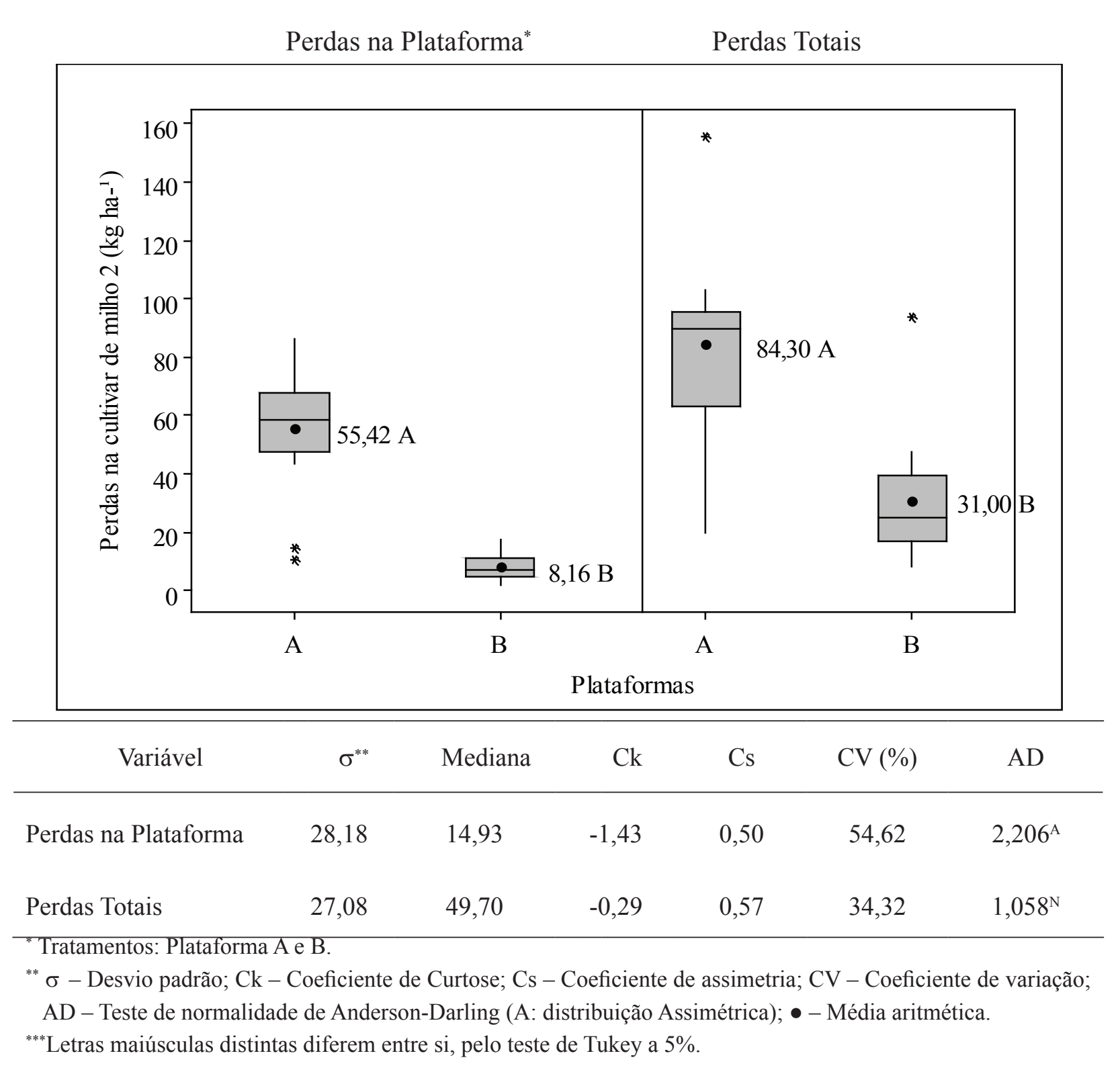

Figura 2. Diagrama de caixa para as perdas na colheita mecanizada do cultivar milho 2 .

Segundo Loureiro et al. (2012), o fato de a velocidade da colhedora provocar vibração na planta de milho pode fazer com que a espiga se desprenda da planta antecipadamente e acabe caindo fora da plataforma de colheita, ocasionando as perdas por espigas. À medida que a velocidade cresce, as perdas diminuem até chegar a um ponto ótimo. Depois desse ponto, o acréscimo de velocidade de deslocamento na máquina provoca impacto mais forte sobre a planta, ocasionando o desprendimento da espiga da planta e fazendo com que essa seja arremessada fora da plataforma de colheita. De acordo com Portella (2001), é na plataforma de colheita onde ocorrem as maiores perdas, pois podem ocorrer perdas por espigas para fora da plataforma e grãos debulhados devido ao impacto da colhedora na planta. No presente trabalho boa parte das perdas encontradas na plataforma foi devido às perdas por espigas.

Já para o milho 2, somente perdas na plataforma apresentaram distribuição assimétrica pelo teste de Anderson Darling (Figura 2). As perdas totais apresentaram distribuição normal, com coeficiente de curtose próximo de zero, apontando para uma distribuição mesocúrtica. 
Os coeficientes de variação foram considerados como altos segundo recomendado por PimentelGomes e Garcia (2002). Houve anormalidade da curva de distribuição para perdas na plataforma, sendo que o coeficiente de curtose apresentou distribuição platicúrtica, ou seja, negativo, apresentando curva de distribuição achatada. Para esse milho as médias também ficaram mais próximas da mediana para a plataforma $\mathrm{B}$, com amplitudes interquartílicas menores (box-plot), apresentando menor variabilidade dos dados.

Para este milho, tanto para as perdas na plataforma quanto para as totais, a plataforma $\mathrm{B}$ superou a A, obtendo-se menores valores de perdas. Mesmo esta cultivar estando ereta no momento da colheita, aconteceu comportamento semelhante que o obtido no milho acamado para perdas na plataforma, em que o desfavorável funcionamento da plataforma A no momento de recolhimento e despigamento das plantas de milho causou a elevação das perdas, chegando a 55,42 e $8,16 \mathrm{~kg}$ ha $^{-1}$ para A e B respectivamente. Diferentemente do milho acamado, para o milho ereto as perdas totais não foram iguais, com a plataforma $B$ apresentando menores perdas comparadas à plataforma $\mathrm{A}(31,00$ e $84,30 \mathrm{~kg} \mathrm{ha}^{-1}$, respectivamente). Este fato pode ter ocorrido por mau funcionamento dos mecanismos internos da colhedora, sendo que este milho além de se apresentar-se ereto também possuía maior produtividade de grãos, o que pode ter aumentado o fluxo de material a ser trilhado, limpo e separado, causando perdas de grão no campo.

Constata-se que as perdas totais encontradas foram baixas concordando com os valores obtidos por Souza (2007) e Tabile et al. (2008), que encontram apenas $0,20 \% \mathrm{e} 0,57 \%$, respectivamente, e dentro do limite tolerável de $60 \mathrm{~kg} \mathrm{ha}^{-1}$ definido por Mesquita et al. (2002).

Para cada variável avaliada, as mesmas foram consideradas como indicadores de qualidade da operação da colheita mecanizada de milho, tendo como parâmetros de qualidade as perdas na plataforma e totais, sendo interpretadas pelo controle estatístico de processo.

Ao se observar as cartas de controle para perdas na plataforma no milho 1 (Figura 3), constata-se que a plataforma $\mathrm{A}$ apresentou um ponto fora de controle, evidenciando a ocorrência de causas especiais para os valores individuais e para a variação do processo (cartas de amplitude móvel).

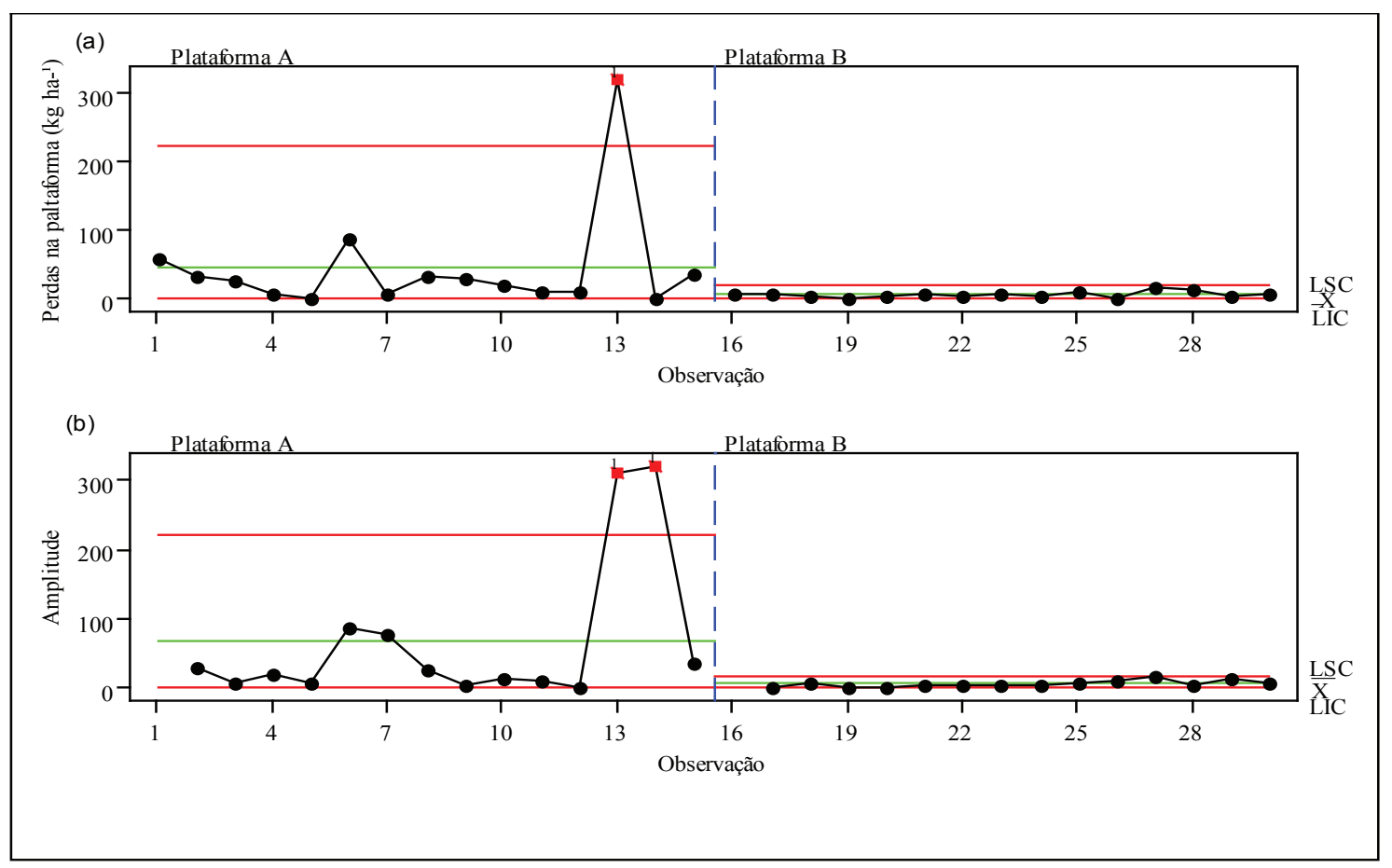

LSC: limite superior de controle. LIC: Limite inferior de controle. $\bar{X}$ : média.

Figura 3. Cartas de controle para perdas na plataforma para o milho $1\left(\mathrm{~kg} \mathrm{ha}^{-1}\right)$. (a) Carta de valores individuais. (b) Carta de amplitude móvel. 


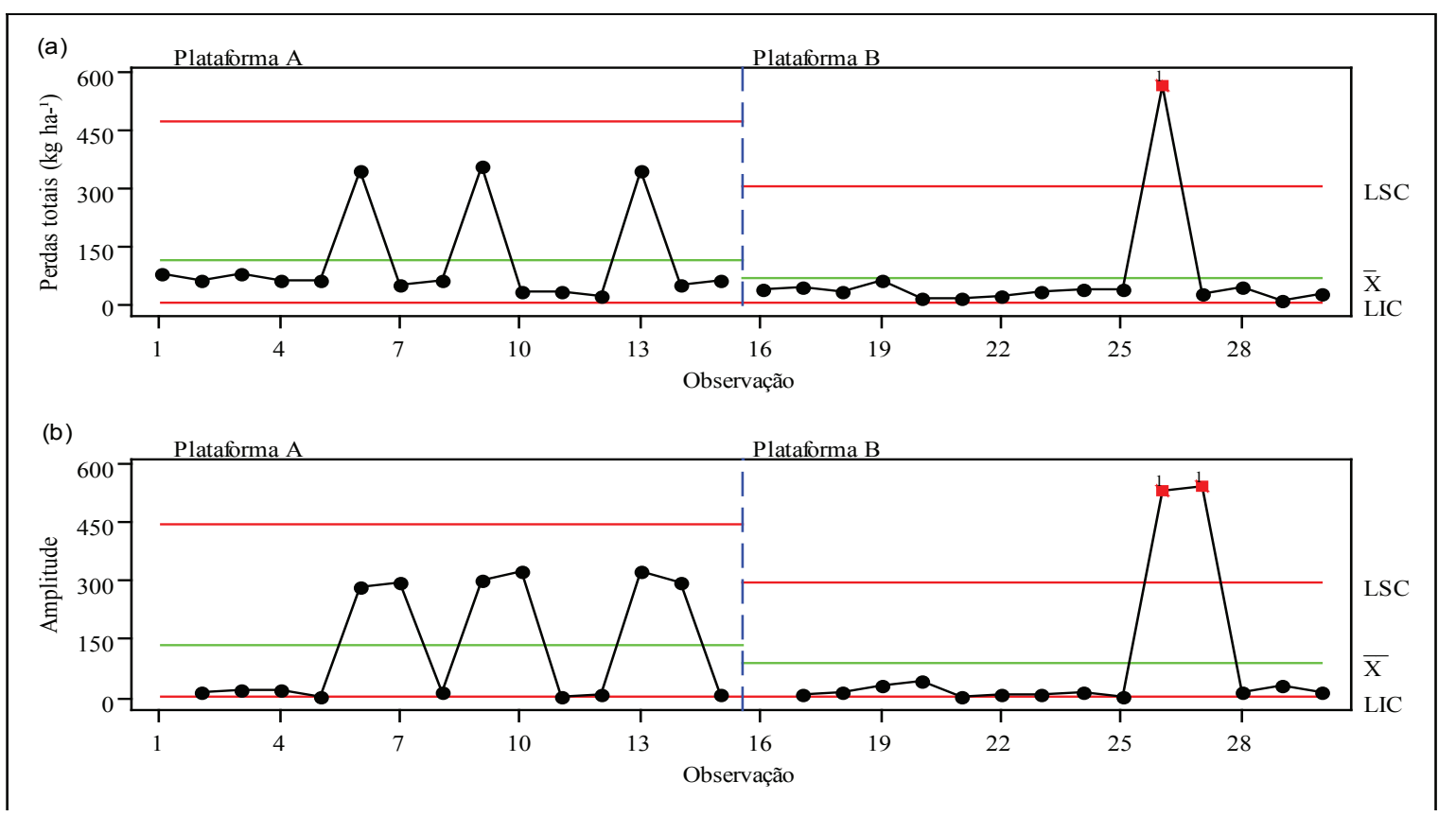

LSC: limite superior de controle. LIC: Limite inferior de controle. $\bar{X}$ : média.

Figura 4. Cartas de controle para perdas totais para o milho $1\left(\mathrm{~kg} \mathrm{ha}^{-1}\right)$. (a) Carta de valores individuais. (b) Carta de amplitude móvel.

Os baixos valores de desvio padrão resultaram em limites superior e inferior de controle (LSC e LIC) reduzidos para a plataforma $\mathrm{B}$, sendo a operação considerada como de melhor qualidade. Porém, para a plataforma A esses limites se apresentaram mais distantes da média, devido, principalmente, ao maior valor encontrado causado pelo ponto fora de controle.

Na plataforma A, a existência de um ponto fora de controle (observação $\mathrm{n}^{\mathrm{o}}$ 13) levou à instabilidade do processo e da variação do mesmo, uma vez que as amplitudes foram maiores (observações $\mathrm{n}^{\circ} 13$ e 14) também ultrapassando o (LSC). Esta instabilidade pode ser explicada pelo fato de que essas causas especiais podem ocorrer devido aos chamados fatores "6 M's" (matéria-prima, mão de obra, método, máquina, medição e meio ambiente). Neste caso específico os fatores mais relevantes possivelmente para explicar o ponto acima do (LSC) são: máquina e matéria prima. A máquina pode estar relacionada aos próprios componentes da plataforma, suas dimensões e regulagens, tais como: ajuste das chapas destacadoras e rolos despigadores, rotação do condutor transversal (caracol), velocidade das correntes recolhedoras. Pelo motivo de a plataforma A ser menor, é incapaz de recolher todo o colmo do milho para destacar as espigas, e por ser mais leve, sofre maior efeito de trepidação, podendo ser motivo de maiores perdas durante a colheita. Já em relação á matéria prima, o motivo de a cultura estar acamada pode ter sido um fato importante para este acontecimento.

Para perdas totais aconteceu o contrário, com a plataforma B apresentando um ponto acima do LSC, significando que o processo está fora de controle, por motivo de causas especiais, não inerentes ao processo (Figura 4).

A observação número 26 levou à instabilidade do processo e da variação do mesmo, uma vez que as amplitudes foram maiores (observações $\mathrm{n}^{\circ} 26$ e 27) também ultrapassando o LSC. Como esse ponto é muito discrepante em relação aos demais, ele pode ser considerado como um "outlier". Estes "outliers" são pontos incomuns que se apresentam distantes das demais observações afastados da média podendo estar acima ou abaixo da mesma tanto para a variável resposta como para explicativa, podendo ser considerado potencialmente como valores que não representam o verdadeiro comportamento do conjunto de dados. Esta situação possivelmente pode ser explicada em função dos fatores "6 M's", sendo relacionado à máquina, representado pelos mecanismos internos da colhedora, em que neste ponto, por alguma regulagem inadequada ou mal funcionamento, causou a elevada quantidade de perdas totais neste ponto fora de controle. $\mathrm{O}$ importante é verificar que, mesmo essa plataforma 
possuindo um ponto fora de controle, a variação do processo foi menor do que na outra, observado pela menor distância entre os limites da carta de amplitude, sendo a operação considerada mais homogênea do que a outra.

As cartas de controle para perdas nas plataformas no milho 2 apresentaram todos os pontos situados entre os limites de controle, tanto para os valores individuais quanto para os valores de amplitude, sendo então considerado um processo controlado, com variações aleatórias causadas por fatores naturais ao processo (Figura 5).

Tanto a média (linha central) quanto a distância dos limites de controle para a plataforma A estão visivelmente mais afastados que na plataforma $\mathrm{B}$, sendo a variação do processo observada nas cartas de amplitude. Portanto a operação com a plataforma $\mathrm{B}$ se mostrou mais homogênea do que com a plataforma A. Então, como o processo foi estável, vale lembrar que este milho estava ereto no momento da colheita, sendo um fator importante e positivo quando se fala em colheita mecanizada, em que o porte da cultura é um fator que interfere na qualidade da colheita. A diferença entre as duas plataformas está na capacidade de arrancar e recolher a espiga de milho da haste da planta, uma vez que o processo de arranquio está ligado principalmente às chapas e rolos despigadores, e o recolhimento ligado ao condutor transversal, sendo que a dimensão destes componentes afetam diretamente a qualidade do processo da colheita, como a massa da plataforma e comprimento da chapa despigadora, sendo os mesmos motivos que o acontecido no milho 1.

Já as perdas totais mostraram o mesmo comportamento, sendo a plataforma B mais homogênea do que com a plataforma $\mathrm{A}$, havendo menor variabilidade dos valores nesta plataforma, que pode ser verificada pelo afastamento da média aos limites de controle, verificado pelas cartas de variação do processo (amplitude móvel) e pelo desvio padrão desta variável (Figura 6).

$\mathrm{O}$ que ocorreu foi que, mesmo com as perdas totais sendo mais homogêneas, ainda assim houve um ponto acima do LSC (ponto 22), ou seja, fora de controle, com causas não inerentes ao processo. O motivo "6 M's" para este "outlier" pode ter sido a máquina e seu mecanismo interno de trilha, separação e limpeza dos grãos de milho, que por algum problema de desajuste, o sistema possibilitou a caída dos grãos ao solo, aumentando as perdas totais na colheita mecanizada do milho, tornando o processo instável. Este ponto levou a instabilidade do processo também observada na carta de amplitude móvel (ponto 23), o qual também ultrapassou o LSC.

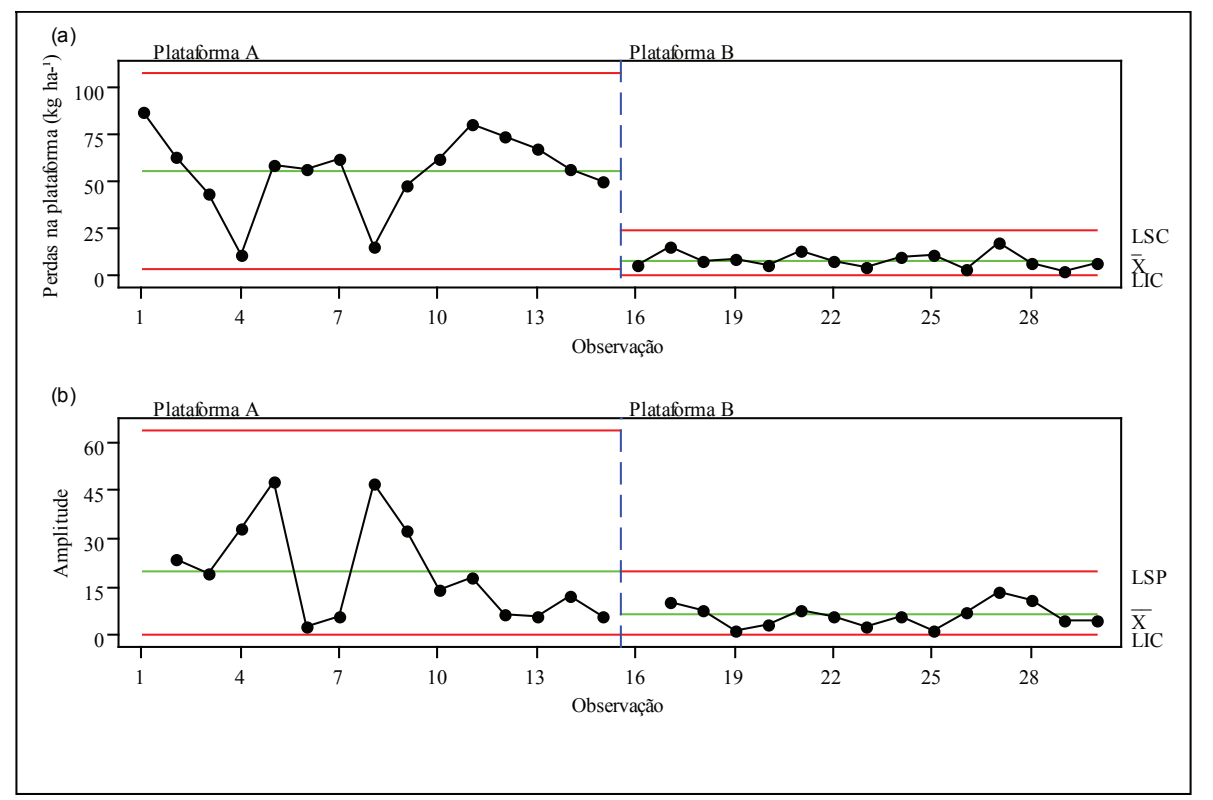

LSC: limite superior de controle. LIC: Limite inferior de controle. $\bar{X}$ : média.

Figura 5. Cartas de controle para perdas na plataforma para o milho $2\left(\mathrm{~kg} \mathrm{ha}^{-1}\right)$ (a) Carta de valores individuais. (b) Carta de amplitude móvel. 


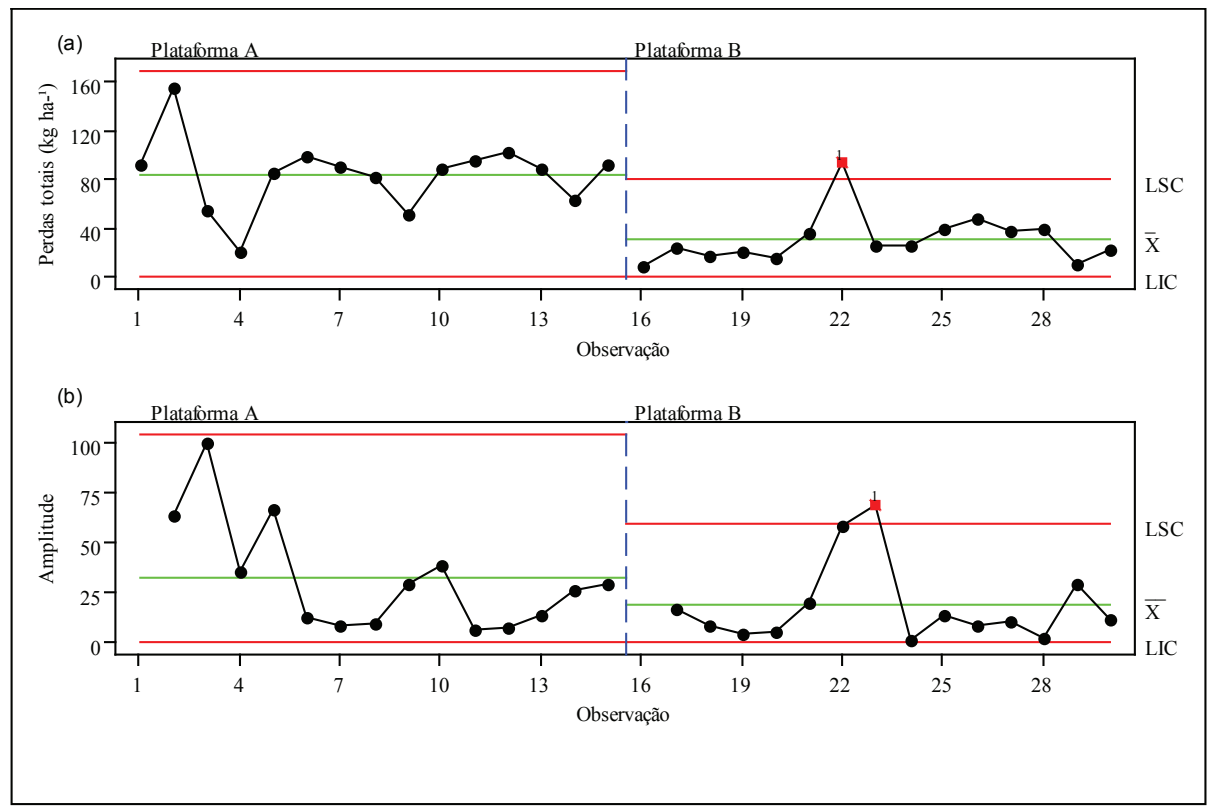

LSC: limite superior de controle. LIC: Limite inferior de controle. $\bar{X}$ : média.

Figura 6. Cartas de controle para perdas totais para o milho $2\left(\mathrm{~kg} \mathrm{ha}^{-1}\right)$ (a) Carta de valores individuais. (b) Carta de amplitude móvel.

\section{CONCLUSÕES}

- Na cultivar de milho 1, a plataforma de corte A apresentou o mais elevado valor de perdas na plataforma e mostrou instabilidade do processo, porém para perdas totais a plataforma $\mathrm{B}$ foi a que se mostrou fora de controle, apresentando operação mais homogênea.

- Para a cultivar 2 tanto as perdas na plataforma quanto as totais foram menores na plataforma $\mathrm{B}$, a qual mostrou instabilidade do processo para perdas totais, todavia com menor variação indicada pelos limites de controle.

\section{REFERÊNCIAS BIBLIOGRÁFICAS}

BONILLA, J.A. Qualidade total na agricultura: fundamentos e aplicações. 2 ed. Belo Horizonte: Centro de Estudos de Qualidade Total na Agricultura, 1994. 344p.

BONILLA, J.A. Métodos quantitativos para qualidade total na agricultura. 2. ed. Contagem: Líttera Maciel, 1995. 250p.

BRACHTVOGEL, E.L.; PEREIRA, F.R.S.; CRUZ, S.C.S.; ABREU, M.L.; BICUDO, S.J. População, arranjo de plantas uniforme e a competição intraespecífica em milho. Revista Trópica, v.6, n.1, p. 75-83, 2012.

CASSIA, M.T.; SILVA, R.P.; CHIODEROLI, C.A.; NORONHA, R.H.F.; SANTOS, E.P. Qualidade da colheita mecanizada de café em sistema de plantio circular. Ciência Rural, Santa Maria, v.43, n.1, jan, 2013.

CHIODEROLI, C.A.; SILVA, R.P.; NORONHA, R.H.F.; CASSIA, M.T.; SANTOS, E.P. Perdas de grãos e distribuição de palha na colheita mecanizada de soja. Bragantia, Campinas, v.71, n.1, p.112-121, 2012.

CONAB - Companhia Nacional de Abastecimento. Acompanhamento da safra de grãos. Oitavo levantamento. Maio 2012. Disponível em: http://www.conab.gov.br/OlalaCMS/uploads/ arquivos/12_05_10_08_49_52_boletim_maio_2012. pdf Acesso em: 31 jul., 2012.

CUSTODIO, A.A.P.; SILVA, R.P.; LEMOS, L.B.; TOLEDO, A.; LIMA, L.P. Controle estatístico aplicado na colheita mecanizada de cafeeiros irrigados. Revista de Agricultura, Piracicaba, v.1, p.172-180, 2012. 
DIAS, V.O.; SOUZA, R.S.; ALONÇO, A.S. Análise da viabilidade econômica do investimento em plataformas de colhedoras de milho. Engenharia Agrícola, Jaboticabal, v.27, n.2, p.463-470, 2007.

EMBRAPA. Empresa Brasileira de Pesquisa Agropecuária. Sistema brasileiro de classificação de solos. $2^{\mathrm{a}} \mathrm{Ed}$. Rio de Janeiro: Embrapa Solos. 2006, 306p.

FREDDI, O.S.; CARVALHO, M.P.; VERONESI JÚNIOR, V.; CARVALHO, G.J. Produtividade do milho relacionada com a resistência mecânica à penetração do solo sob preparo convencional. Engenharia Agrícola, v.26, p.113-121, 2006.

MESQUITA, C.M.; COSTA, N.P.; MANTOVANI, E.C.; ANDRADE, J.G.M.; FRANÇA NETO, J.B.; SILVA, J.G.; FONSECA, J.R.; PORTUGAL, F.A.F.; GUIMARÃES SOBRINHO, J.B. Manual do produtor: Como evitar desperdícios nas colheitas da soja, do milho e do arroz. Londrina: EMBRAPA-CNPSo, p.19-22, 1998.

MESQUITA, C.M.; COSTA, N.P.; PEREIRA, J.E.; MAURINA, A.C.; ANDRADE, J.G.M. Perfil da colheita mecânica da soja no Brasil: safra 1998/1999. Engenharia Agrícola, Jaboticabal, v.22, n.3, p.398-406, 2002.

MINGOTI, S.A.; FIDELIS, M.T. Aplicando a geoestatística no controle estatístico de processo. Revista Produto e Produção, v.5, p.55-70, 2001.

NORONHA, R.H.F.; SILVA, R.P.; CHIODEROLI, C.A.; SANTOS, E.P.; CASSIA, M.T. Controle estatístico aplicado ao processo de colheita mecanizada diurna e noturna de cana-de-açúcar. Bragantia, São Paulo, v.70, p.1-8, 2011.

PIMENTEL-GOMES, F.; GARCIA, C.H. Estatística aplicada a experimentos agronômicos e florestais: exposição com exemplos e orientações pra uso de aplicativos. Piracicaba: FEALQ, 309p, 2002.

PORTELLA, J.A. Colheita de grãos mecanizada - implementos, manutenção e regulagem. Viçosa, MG: Aprenda Fácil, 190 p, 2001.

SILVA, R.P.; CASSIA, M.T.; VOLTARELLI, M.A.; COMPAGNON, A.M.; FURLANI, C.E.A. Qualidade da colheita mecanizada de feijão (Phaseolus vulgaris) em dois sistemas de preparo do solo. Revista Ciência Agronômica, v.44, n.1, p.61-69, 2013.

SOUZA, L.A. Colheita mecanizada de milho: perdas em função do manejo de cultura de cobertura. 34 f. Monografia (Graduação em Agronomia) - Faculdade de Ciências Agrárias e Veterinárias, Universidade Estadual Paulista, Jaboticabal, 2007.

STAGGENBORG, S.A.; DHUYVETTER, K.C.; GORDON, W.B. Grain sorghum and corn comparisons: yield, economic, and environmental responses. Journal of Agronomy, 100: 1600-1604, 2008.

TABILE, R.A.; TOLEDO, A.; SILVA, R.P.; FURLANI, C.E.A.; GROTTA, D.C.C.; CORTEZ, J.W. Perdas na colheita de milho em função da rotação do cilindro trilhador e umidade dos grãos. Scientia Agraria, Curitiba, v.9, n.4, p.505-510, 2008.

VIEIRA, S.R.; MILLETE, J.; TOPP, G.C.; REYNOLDS, W.D. Handbook for geoestatical analysis of variability in soil and climate data. In: Alvarez V.V.H.; Schaefer, C.E.G.R.; Barros, N.F.; Mello, J.W.V.; Costa, L.M. (Ed.). Tópicos em ciência do solo. Viçosa: Sociedade Brasileira de Ciência do Solo. v.2, p.1-45, 2002. 